\title{
TRATAMENTO DE ÁGUAS RESIDUÁRIAS DE SUINOCULTURA EM REATORES ANAERÓBIOS DE FLUXO ASCENDENTE COM MANTA DE LODO (UASB) EM DOIS ESTÁGIOS SEGUIDOS DE REATOR OPERADO EM BATELADA SEQUENCIAL (RBS)
}

\section{ROBERTO A. DE OLIVEIRA ${ }^{1}$, ADRIANA M. DE SANTANA ${ }^{2}$}

\begin{abstract}
RESUMO: Neste trabalho, avaliou-se o desempenho de dois reatores anaeróbios de fluxo ascendente com manta de lodo (UASB), em série, seguidos de um reator operado em batelada sequencial (RBS) com etapa aeróbia, no tratamento de águas residuárias de suinocultura. $\mathrm{O}$ sistema de tratamento anaeróbio em dois estágios foi alimentado com águas residuárias de suinocultura com concentrações médias de sólidos suspensos totais (SST), de 4.427 a $16.425 \mathrm{mg} \mathrm{L}^{-1}$. As cargas orgânicas volumétricas (COV) aplicadas no reator UASB do primeiro estágio variaram de 14,8 a 24,4 g DQO $(\mathrm{L} \mathrm{d})^{-1}$. Os tempos de detenção hidráulica (TDH) foram de 28 e $11 \mathrm{~h}$ e de 14 e $6 \mathrm{~h}$ no primeiro e segundo reatores UASB, respectivamente. O RBS foi operado com 1 e 2 ciclos diários de alimentação e com concentrações de SST do afluente, de 1.348 a $2.036 \mathrm{mg} \mathrm{L}^{-1}$. As maiores eficiências de remoção de $\mathrm{DQO}_{\text {total }}$ ocorreram com os maiores $\mathrm{TDH}$, com valores médios de 78 a $88 \%$ nos reatores UASB, em dois estágios. Com o tratamento do efluente dos reatores UASB no RBS, as eficiências médias de remoção aumentaram para 93 a 97\%, 92 a 98\%, 57 a 78\%, 71 a 88\% e 68 a 85\% para a DQO total, SST, P-total, nitrogênio total Kjeldahl (NTK) e nitrogênio total (NT), respectivamente. Para os coliformes termotolerantes, as remoções foram de 93,80 a 99,99\%.
\end{abstract}

PALAVRAS-CHAVE: remoção de nutrientes, tratamento anaeróbio-aeróbio, pós-tratamento, nitrificação.

\section{SWINE WASTEWATER TREATMENT IN UPFLOW ANAEROBIC SLUDGE BLANKET REACTOR (UASB) IN TWO-STAGES FOLLOWED BY SEQUENCING BATCH REACTOR (SBR)}

\begin{abstract}
This work aimed to evaluate the performance of two aerobic-anaerobic combination system of upflow anaerobic sludge blanket digestion reactor (UASB) in line followed by an aerobic sequencing bath reactor (SBR), used in swine wastewater treatment. The UASB system was fed with swine wastewater containing from 4427 to $16425 \mathrm{mg} \mathrm{L}^{-1}$ of total suspended solids (TSS). The treatment system was evaluated using organic loading (OLR) of 14,8 to $24,4 \mathrm{~g}$ total COD (L d) ${ }^{-1}$ in the first UASB reactor. The hydraulic detention times (HDT) were of 28 and $11 \mathrm{~h}$, and 14 and $6 \mathrm{~h}$, in the first and second UASB reactor, respectively. The SBR was operated with one and two cycles daily and the affluent had TSS concentrations of 1348 to $2036 \mathrm{mg} \mathrm{L}^{-1}$. The higher total chemical oxygen demand (COD) removal efficiencies were of 78 to $81 \%$ in UASB reactors in two-stage and occurred with higher HDT. With the aerobic SBR used as post-treatment of the effluent from UASB reactors allowed removal efficiency averages of 93 to $97 \%, 92$ to $98 \%, 57$ to $78 \%, 71$ to $88 \%$ and from 68 to $85 \%$ of total COD, TSS, total P, total Kjeldahl nitrogen (TKN) and total nitrogen (TN), respectively. The thermotolerants coliforms the removals were of 93.80 to $99.99 \%$.
\end{abstract}

KEYWORDS: nutrients removal, anaerobic-aerobic treatment, post-treatment, nitrification.

\footnotetext{
${ }^{1}$ Eng ${ }^{\mathrm{o}}$ Agrônomo e Tecnólogo em Construção Civil, Prof. Doutor, Departamento de Engenharia Rural, UNESP, Câmpus de Jaboticabal - SP, Fone: (0XX16) 3209-2638, raoder@fcav.unesp.br.

${ }^{2}$ Bióloga, Mestre e Doutora em Microbiologia Agropecuária pela UNESP, Câmpus de Jaboticabal - SP.

Recebido pelo Conselho Editorial em: 6-11-2008

Aprovado pelo Conselho Editorial em: 10-1-2011
} 


\section{INTRODUÇÃO}

A suinocultura é uma atividade com importância econômica e social; no entanto, a exploração é considerada pelos órgãos de fiscalização ambiental uma atividade de grande potencial poluidor.

As águas residuárias de suinocultura são caracterizadas pelas altas concentrações de sólidos suspensos (0,5 a 3,0\%), demanda química de oxigênio (DQO), nitrogênio, fósforo e coliformes, conforme descrito por OLIVEIRA \& FORESTI (2004). Nos confinamentos de suínos, principalmente nos de grande porte, onde predomina o uso intensivo de água para a higienização das instalações, são produzidos grandes volumes de efluentes. Nessas instalações, as fezes, urina e restos de ração são arrastados pela água utilizada na limpeza até um tanque de espera, a partir do qual muitas vezes são despejados no corpo de água ou dispostos no solo como fertilizante, o que pode ocasionar sérios problemas ambientais.

O processo de digestão anaeróbia está sendo amplamente utilizado para a conversão de matéria orgânica e, atualmente, é uma tecnologia bem estabelecida para o tratamento de uma ampla variedade de águas residuárias geradas pelas atividades humanas, urbanas e também rurais, como as da agropecuária.

Nas regiões tropicais e subtropicais, onde a temperatura favorece a digestão anaeróbia, aliadas ao baixo custo de implantação, operação e a reduzida geração de lodo têm colocado os reatores anaeróbios de fluxo ascendente com manta de lodo (UASB) em posição de destaque para o tratamento de águas residuárias. Com a utilização de reatores UASB em dois estágios (dois reatores em série), é possível melhorar as remoções de sólidos suspensos, DQO, fósforo e coliformes de águas residuárias de suinocultura (SANTANA \& OLIVEIRA, 2005; RAMIRES, 2005, DUDA \& OLIVEIRA, 2009). Contudo, dificilmente esses reatores produzem efluentes que atendem aos padrões estabelecidos pela legislação ambiental brasileira de qualidade de água, além de terem pouco efeito na remoção dos macronutrientes, como o nitrogênio, e coliformes, necessitando de uma etapa de pós-tratamento (MASCARENHAS et al., 2004).

Os sistemas de tratamento combinados (anaeróbio e aeróbio) são promissores, principalmente quando, além da redução da matéria orgânica, deseja-se a remoção de nutrientes, em particular do nitrogênio orgânico e amoniacal. Entre as vantagens dos sistemas anaeróbio e aeróbio, destacam-se a baixa potência de aeração requerida, a menor produção de lodo biológico e o baixo custo de implantação, quando comparado aos sistemas aeróbios convencionais (CHERNICHARO, 2006).

$O$ reator operado em batelada sequencial (RBS) tem sido investigado para o tratamento de águas residuárias de suinocultura (BERNET et al., 2000; ZHANG et al., 2006; DENG et al., 2008) para promover a remoção biológica de matéria orgânica, nutrientes e coliformes. A característica fundamental de um RBS é a flexibilidade das etapas de um ciclo de operação, o que permite o estabelecimento de condições de processo que promovam a remoção biológica de nutrientes.

Neste contexto, o objetivo da realização deste trabalho foi avaliar o desempenho de reatores UASB, em dois estágios, seguidos de RBS com etapa aeróbia, em escala-piloto, para o tratamento de águas residuárias de suinocultura, com diferentes concentrações de sólidos suspensos totais, visando à remoção de matéria orgânica, nutrientes e coliformes.

\section{MATERIAL E MÉTODOS}

A pesquisa foi desenvolvida nas instalações experimentais e laboratórios da área de Digestão Anaeróbia do Departamento de Engenharia Rural da Faculdade de Ciências Agrárias e Veterinárias da Universidade Estadual Paulista - UNESP, Câmpus de Jaboticabal. O clima da região, segundo classificação de Köeppen, é Cwa (subtropical úmido, seco no inverno e com chuva no verão), com precipitação média anual de $1.300 \mathrm{~mm}$ e temperatura média anual de $21^{\circ} \mathrm{C}$ (UNESP, 2009).

O sistema de tratamento anaeróbio em dois estágios foi constituído por uma caixa de armazenamento do afluente, dois reatores de fluxo ascendente com manta de lodo (UASB) em 
escala-piloto, instalados em série, com volumes de 510 e $209 \mathrm{~L}$, para o primeiro (R1) e segundo reatores (R2), respectivamente (Figura 1). Para a alimentação do sistema de tratamento anaeróbio, foi utilizada uma bomba helicoidal e, para a monitorização da produção de biogás, foram utilizados selos hidráulicos e gasômetros.

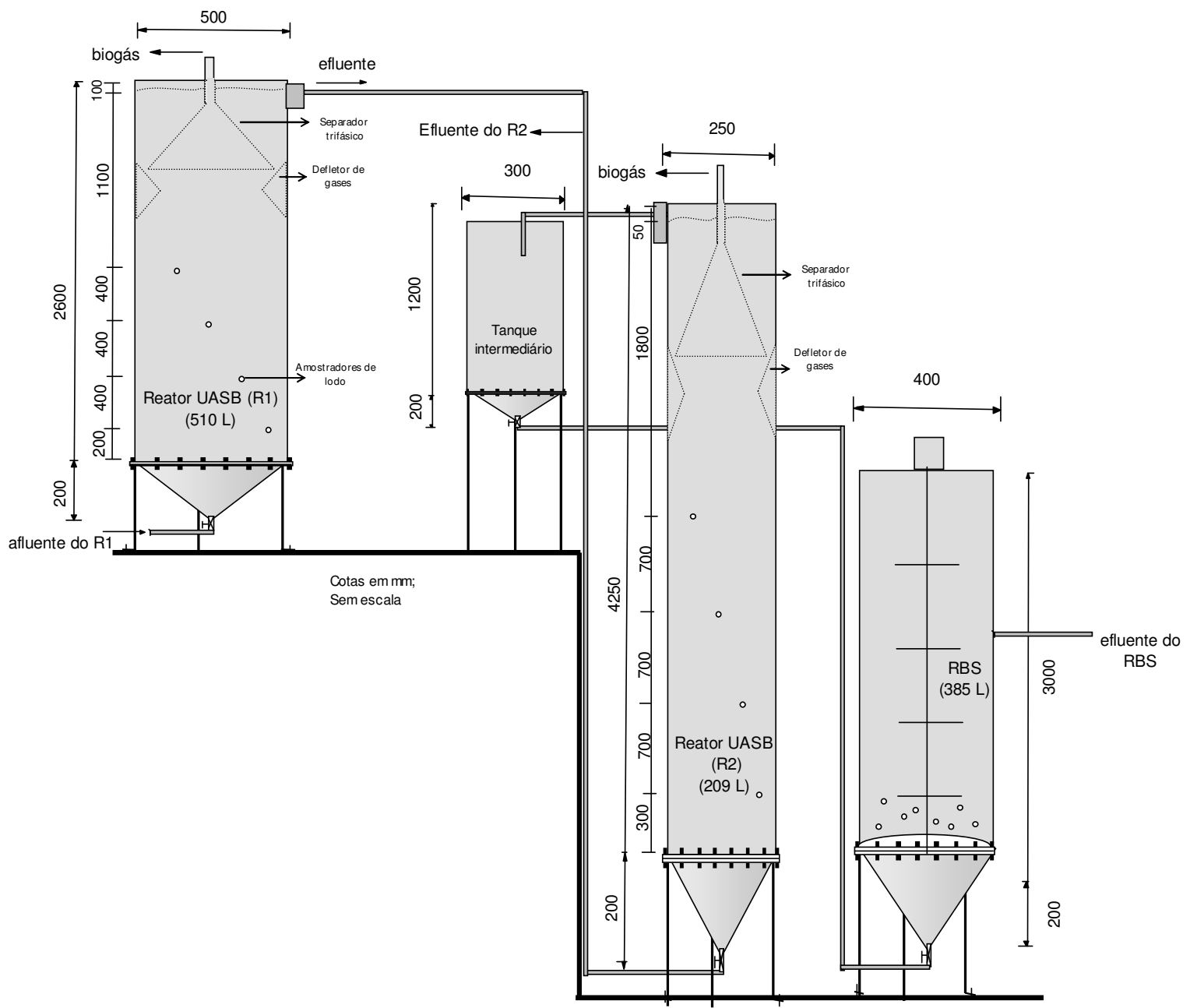

FIGURA 1. Esquema dos reatores anaeróbios de fluxo ascendente com manta de lodo (UASB), em dois estágios, seguidos de reator operado em batelada sequencial (RBS) com etapa aeróbia. Scheme of two-stage upflow anaerobic sludge blanket (UASB) reactors followed by aerobic sequencing batch reactor (SBR).

O pós-tratamento do efluente dos reatores UASB, em dois estágios, foi realizado em reator operado em batelada sequencial (RBS) com etapa aeróbia, com volume útil de 210 L. Para a aeração do RBS, foi utilizado um compressor, e o ar foi distribuído no interior do reator por meio de um difusor de membrana, instalado na base do RBS. A quantidade de ar introduzida foi monitorada em medidor de vazão. No topo do RBS, foi instalado um conjunto de motor-redutor conectado a um eixo com pás ao longo da altura do reator, com o objetivo de proporcionar a mistura durante a etapa de reação anaeróbia. Foram instalados temporizadores analógicos para o acionamento do compressor e do conjunto motor-redutor.

As águas residuárias de suinocultura utilizadas como afluente do sistema de tratamento anaeróbio foram coletadas, diariamente, em confinamento de suínos, na fase de crescimento e terminação, do Setor de Suinocultura da UNESP, Câmpus de Jaboticabal.

O experimento foi dividido em quatro fases, variando-se o tempo de detenção hidráulica (TDH) nos reatores UASB e no RBS, e as características do afluente (SST, SSV e DQO total), permitindo avaliar o desempenho do sistema de tratamento frente a diferentes condições; com 
acréscimos de carga orgânica volumétrica (COV) no R1 com o mesmo TDH (fases 1 e 2 e fases 3 e 4) e também com COV similares no R1 e diferentes TDH (fases 1 e 4 e fases 2 e 3) (Tabelas 1 e 2). Além disso, foi avaliado o efeito do aumento da COV no RBS, na fase 4, reduzindo-se o TDH de 56 para 28 h (Tabela 1), por meio da diminuição do ciclo operacional de 24 para 12 h (Figura 2).

Nas fases 1 e 2, e nas fases 3 e 4, os TDH aplicados nos reatores UASB (R1 e R2) foram de 28 e $11 \mathrm{~h}$, e de 14 e $6 \mathrm{~h}$, respectivamente. Os reatores foram operados continuamente por 141; 105; 61 e 65 dias nas fases $1 ; 2 ; 3$ e 4, respectivamente (Tabela 1 ).

TABELA 1. Tempos de detenção hidráulica (TDH) aplicados nos reatores UASB (R1 e R2) e no reator operado em batelada sequencial (RBS) e tempo de operação nas fases $1 ; 2 ; 3$ e 4. Hydraulic detention time in the UASB reactors ( $R 1$ and $R 2)$ and sequencing batch reactor (SBR), and operation time in phases 1, 2, 3 and 4.

\begin{tabular}{cccccc}
\hline Parâmetros & & Fase 1 & Fase 2 & Fase 3 & Fase 4 \\
\hline \multirow{3}{*}{ TDH (h) } & R1 & 28 & 28 & 14 & 14 \\
\cline { 2 - 7 } & R2 & 11 & 11 & 6 & 6 \\
\cline { 2 - 6 } & RBS & 56 & 56 & 56 & 28 \\
\hline Tempo de operação (d) & & 141 & 105 & 61 & 65 \\
\hline
\end{tabular}

Nas fases 1; 2 e 3, o RBS foi operado com TDH de 56 h, e o ciclo operacional de $24 \mathrm{~h}$, com $8 \mathrm{~h} 30$ de reação anaeróbia; 6,0 h de reação aeróbia; 6,0 h de sedimentação e 1,0h para o descarte e alimentação. Na fase 4, o TDH foi de 28 h, e o ciclo operacional de $12 \mathrm{~h}$ teve $4 \mathrm{~h} 30$ de reação anaeróbia; $4 \mathrm{~h} 30$ de reação aeróbia; $2,0 \mathrm{~h}$ de sedimentação e $1,0 \mathrm{~h}$ de descarte e alimentação, conforme ilustrado na Figura 2.

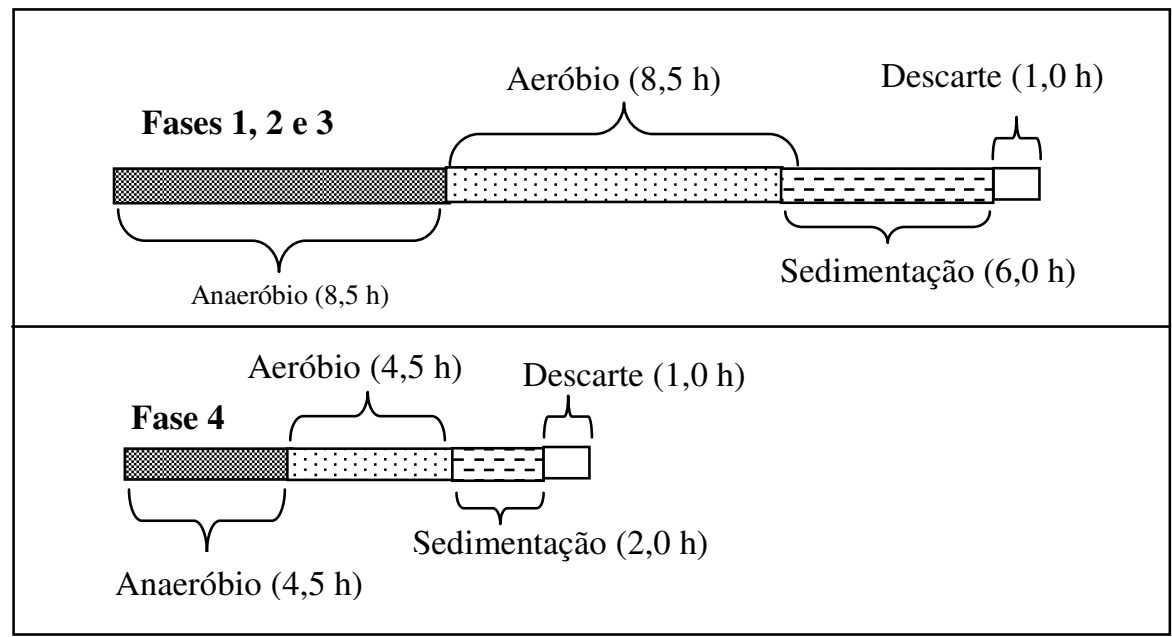

FIGURA 2. Características do ciclo operacional do reator aeróbio em batelada sequencial (RBS) nas fases $1 ; 2 ; 3$ e 4 . Characteristics of the operational cycle of the sequencing batch reactor (SBR) in phases $1,2,3$ and 4 .

No início do experimento, para a partida dos reatores UASB, preencheram-se de 20 a $30 \%$ do volume de cada reator com lodo de inóculo, com concentração de sólidos voláteis (SV) de $15 \mathrm{~g} \mathrm{~L}^{-1}$, provenientes de outros reatores UASB que estavam tratando águas residuárias de suinocultura. $\mathrm{O}$ RBS foi inoculado com lodo sedimentado (100 L), com SV de $12 \mathrm{~g} \mathrm{~L}^{-1}$, proveniente do tanque de aeração de um sistema de lodos ativados que estava tratando esgoto sanitário doméstico, da Estação de Tratamento de Esgoto (ETE) Bueno de Andrade, do município de Araraquara. Com estes procedimentos, pretendeu-se diminuir o tempo necessário para o estabelecimento de condições estáveis de desempenho dos reatores.

Durante a operação do RBS, em todas as fases, foi mantido o lodo ocupando $120 \mathrm{~L}$ (aproximadamente $60 \%$ do volume do RBS), retirando-se $90 \mathrm{~L}$ do sobrenadante na etapa de 
descarte do efluente. A distribuição dos tempos e da sequência das etapas do ciclo operacional, e dos volumes do lodo e do efluente descartado foram estabelecidos com base nas recomendações descritas por METCALF \& EDDY (2003) e CHERNICHARO (2001). Para estimar a DQO do afluente do RBS (efluente do R2) e consequentemente manter a COV no RBS dentro dos limites recomendados por METCALF \& EDDY (2003) e CHERNICHARO (2001), nas fases 1; 2; 3 e 4, foram utilizados os resultados obtidos por SANTANA \& OLIVEIRA (2005) e RAMIRES (2005).

As amostras do afluente e efluentes dos reatores UASB foram coletadas duas vezes por semana e compostas por subamostras coletadas durante o período de $6 \mathrm{~h}$ (das 8 às 14h). No RBS, foram coletadas amostras simples, no término do ciclo operacional, na etapa de descarte.

A avaliação do desempenho da unidade experimental baseou-se na monitorização dos afluentes e efluentes dos reatores UASB, em dois estágios, e do RBS, determinando-se: demanda química de oxigênio total $\left(\mathrm{DQO}_{\text {total }}\right)$, demanda química de oxigênio dissolvida (DQO dissolvida), sólidos suspensos totais (SST), sólidos suspensos voláteis (SSV), nitrogênio total Kjeldahl (NTK), nitrogênio amoniacal ( $\mathrm{N}$-am.), nitrogênio orgânico ( $\mathrm{N}$-org.), fósforo total (P-total), potencial hidrogeniônico $(\mathrm{pH})$ e os coliformes totais e termotolerantes, os quais foram realizados conforme métodos descritos por APHA, AWWA, WPCF (1998) e OLIVEIRA (1997).

Os valores das alcalinidades total, parcial e intermediária foram determinados utilizando-se método titulométrico proposto por JENKINS et al. (1983). O volume do biogás produzido nos reatores UASB foi monitorado diariamente por meio de medidas em gasômetros, como descrito por OLIVEIRA (1997), e a composição do biogás foi analisada semanalmente por cromatografia gasosa, conforme descrito por APHA, AWWA, WPCF (1998). Para a determinação do nitrito (N$\mathrm{NO}_{2}{ }^{-}$) e nitrato $\left(\mathrm{N}^{-\mathrm{NO}_{3}}{ }^{-}\right.$) no efluente do RBS, utilizou-se o método espectrofotométrico e para a determinação do oxigênio dissolvido (OD) empregou-se o método potenciométrico com eletrodo de membrana, conforme descrito por APHA, AWWA, WPCF (1998).

\section{RESULTADOS E DISCUSSÃO}

Em virtude das alterações nas características das águas residuárias de suinocultura ao longo das fases de crescimento e terminação, os valores médios de $\mathrm{DQO}_{\text {total }}$ do afluente foram de 17.334; 28.514; 12.654 e $9.049 \mathrm{mg} \mathrm{L}^{-1}$ nas fases $1 ; 2 ; 3$ e 4, respectivamente, com coeficientes de variação (cv) de 44 a $47 \%$ (Tabela 2). As variações da DQO do afluente também ocorreram em outros trabalhos (SANTANA \& OLIVEIRA, 2005; RAMIRES, 2005; DUDA \& OLIVEIRA, 2009) e foram atribuídas às mudanças de idade e do manejo dos animais.

Os valores médios de $\mathrm{DQO}_{\text {total }}$ no efluente do R1, operado com TDH de $28 \mathrm{~h}$, foram similares, de 5.318 e $5.582 \mathrm{mg} \mathrm{L}^{-1}$, nas fases 1 e 2 , respectivamente, e diminuíram para 4.189 e $3.749 \mathrm{mg} \mathrm{L}^{-1}$ nas fases 3 e 4 (Tabela 2), respectivamente, em virtude de menores valores de DQO total no afluente. Os valores médios das eficiências de remoção de $\mathrm{DQO}_{\text {total }}$ no $\mathrm{R} 1$ foram de $66 ; 79 ; 64$ e $52 \%$ nas fases $1 ; 2 ; 3$ e 4 , respectivamente. Os maiores valores de eficiência de remoção de $\mathrm{DQO}_{\text {total }}$, de $79 \%$, foram observadas na fase 2 , com a aplicação das maiores COV, na média de $24,4 \mathrm{~g} \mathrm{DQO}_{\text {total }}$ $(\mathrm{L} \mathrm{d})^{-1}$, e com temperaturas médias do ar de $23,7^{\circ} \mathrm{C}$, indicando que as remoções de $\mathrm{DQO}_{\text {total }}$ não foram limitadas pelas altas COV aplicadas.

No afluente do RBS, os valores médios de $\mathrm{DQO}_{\text {total }}$ foram de 3.622; 3.298; 3.851 e $5.210 \mathrm{mg} \mathrm{L}^{-1}$ durante as fases $1 ; 2 ; 3$ e 4, respectivamente (Tabela 2). Ocorreram reduções acentuadas na $\mathrm{DQO}_{\text {total }}$ média do efluente do RBS para 519; 639; 400 e $455 \mathrm{mg} \mathrm{L}^{-1}$, resultando em eficiências de remoção de $83 ; 73 ; 88$ e $85 \%$, nas fases $1 ; 2 ; 3$ e 4, respectivamente.

As eficiências médias de remoção de $\mathrm{DQO}_{\text {total }}$ e $\mathrm{DQO}_{\text {diss }}$ para o sistema de tratamento anaeróbio, em dois estágios (R1+R2), foram de 78; 88; 67 e 53\% e de 72; 71; 69 e $63 \%$ nas fases 1 ; 2; 3 e 4 (Figura 3), com as temperaturas médias do ar de 21,3;23,7;24,3 e 24,2 ${ }^{\circ} \mathrm{C}$, respectivamente. Mesmo com as menores temperaturas, foi possível obter altas remoções de $\mathrm{DQO}_{\text {total }}$ e de $\mathrm{DQO}_{\text {diss. }}$ 
TABELA 2. Valores médios e coeficientes de variação (C.V.) da temperatura média do ar, da carga orgânica volumétrica $(\mathrm{COV})$; da demanda química de oxigênio total $\left(\mathrm{DQO}_{\text {total }}\right)$ e dissolvida ( DQO $_{\text {diss. }}$ ); dos sólidos suspensos totais (SST) e voláteis (SSV) no afluente e nos efluentes, obtidos durante a operação do sistema de tratamento com reatores UASB, em dois estágios (R1 e R2), seguidos de reator operado em batelada sequencial (RBS), nas fases 1;2; 3 e 4 . Average values and variation coefficients (c.v.) of the medium air temperature, volumetric organic loading (VOL); of the total and dissolved chemical oxygen demand (totalCOD and dissCOD), total and volatile suspended solids (TSS and VSS) in the influent and effluents, during the operation of UASB reactors in series (R1 and R2) followed by sequential batch reactor $(\mathrm{SBR})$ in phases $1,2,3$ and 4.

\begin{tabular}{|c|c|c|c|c|c|c|c|c|c|}
\hline \multirow{2}{*}{\multicolumn{2}{|c|}{ Parâmetros }} & \multicolumn{2}{|c|}{ Fase 1} & \multicolumn{2}{|c|}{ Fase 2} & \multicolumn{2}{|c|}{ Fase 3} & \multicolumn{2}{|c|}{ Fase 4} \\
\hline & & Média & C.V. & Média & C.V. & Média & C.V. & Média & C.V. \\
\hline \multicolumn{2}{|l|}{ Temperatura média do ar $\left({ }^{\circ} \mathrm{C}\right)$} & 21,3 & 16 & 23,7 & 12 & 24,3 & 9 & 24,2 & 6 \\
\hline \multirow{3}{*}{$\operatorname{COV}\left(\mathrm{g}\right.$ DQO total $\left.(\mathrm{L} \mathrm{d})^{-1}\right)$} & R1 & 14,8 & 46 & 24,4 & 47 & 21,7 & 47 & 15,5 & 44 \\
\hline & $\mathrm{R} 2$ & 10,2 & 44 & 12,3 & 73 & 17,4 & 99 & 16,2 & 48 \\
\hline & RBS & 1,6 & 82 & 1,4 & 73 & 1,7 & 55 & 4,5 & 68 \\
\hline \multirow{4}{*}{$\mathrm{DQO}_{\text {total }}\left(\mathrm{mg} \mathrm{L}^{-1}\right)$} & Afluente & 17.334 & 46 & 28.514 & 47 & 12.654 & 45 & 9.049 & 44 \\
\hline & $\mathrm{R} 1$ & 5.318 & 56 & 5.582 & 76 & 4.189 & 44 & 3.749 & 47 \\
\hline & $\mathrm{R} 2$ & 3.622 & 83 & 3.298 & 74 & 3.851 & 55 & 5.210 & 65 \\
\hline & RBS & 519 & 68 & 639 & 45 & 400 & 53 & 455 & 61 \\
\hline \multirow{4}{*}{$\mathrm{DQO}_{\text {dissolvida }}\left(\mathrm{mg} \mathrm{L}^{-1}\right)$} & Afluente & 2.266 & 48 & 2.086 & 26 & 1.931 & 48 & 2.543 & 40 \\
\hline & R1 & 1.062 & 56 & 919 & 43 & 643 & 42 & 1.247 & 43 \\
\hline & $\mathrm{R} 2$ & 605 & 62 & 589 & 44 & 535 & 47 & 929 & 59 \\
\hline & RBS & 302 & 68 & 301 & 32 & 192 & 35 & 193 & 38 \\
\hline \multirow{4}{*}{$\mathrm{SST}\left(\mathrm{mg} \mathrm{L}^{-1}\right)$} & Afluente & 8.270 & 58 & 16.425 & 58 & 5.978 & 51 & 4.427 & 70 \\
\hline & $\mathrm{R} 1$ & 2.482 & 40 & 3.335 & 78 & 1.627 & 40 & 1.778 & 40 \\
\hline & $\mathrm{R} 2$ & 1.348 & 62 & 1.760 & 89 & 1.844 & 68 & 2.036 & 43 \\
\hline & RBS & 112 & 95 & 165 & 85 & 94 & 76 & 227 & 156 \\
\hline \multirow{4}{*}{$\operatorname{SSV}\left(\mathrm{mg} \mathrm{L}^{-1}\right)$} & Afluente & 6.697 & 56 & 12.282 & 65 & 3.357 & 77 & 2.702 & 90 \\
\hline & $\mathrm{R} 1$ & 2.093 & 41 & 2.811 & 77 & 1.019 & 62 & 1.205 & 56 \\
\hline & $\mathrm{R} 2$ & 977 & 74 & 1.400 & 79 & 1.400 & 60 & 1.485 & 82 \\
\hline & RBS & 86 & 117 & 127 & 115 & 62 & 103 & 150 & 230 \\
\hline
\end{tabular}

O aumento da COV de 15,5 até 24,4 $\mathrm{g} \mathrm{DQO}_{\text {total }}(\mathrm{L} \mathrm{d})^{-1}$ não impediu os acréscimos nas remoções de $\mathrm{DQO}_{\text {total }}$ e $\mathrm{DQO}_{\text {diss }}$ no sistema de tratamento anaeróbio, em dois estágios $(\mathrm{R} 1+\mathrm{R} 2)$ (Figura 3). Contudo, ocorreu redução acentuada da remoção de $\mathrm{DQO}_{\text {total }}$, de 78 e $88 \%$ nas fases 1 e 2 para 67 e $53 \%$ nas fases 3 e 4, respectivamente, em virtude da diminuição do TDH (Tabela 1). Assim, evidenciou-se que a aplicação de COV de até $24,4 \mathrm{~g} \mathrm{DQO}_{\text {total }}(\mathrm{L} \mathrm{d})^{-1}$ no R1 não foi limitante para a obtenção de eficiências de remoção acima de $80 \%$ (Figura 3), desde que o TDH não fosse menor do que $28 \mathrm{~h}$ no R1 e $11 \mathrm{~h}$ no R2.

No R1, os valores médios do percentual de $\mathrm{CH}_{4}$ no biogás foram de 75; 76; 80 e 85\%, com os coeficientes de variação (c.v.) de 3 a $6 \%$. No R2, os valores médios do percentual de $\mathrm{CH}_{4}$ no biogás foram de $83 ; 78 ; 81$ e $85 \%$ para as fases $1 ; 2 ; 3$ e 4, respectivamente. Os valores médios da produção volumétrica de $\mathrm{CH}_{4}$ para o conjunto de reatores $(\mathrm{R} 1+\mathrm{R} 2)$ foram de 0,$245 ; 0,368 ; 0,3770$ e $0,194 \mathrm{~L} \mathrm{CH}_{4}$ (L reator d) ${ }^{-1}$, com a aplicação das COV crescentes de 14,$8 ; 15,5 ; 21,7$ e $24,4 \mathrm{~g}$ DQOtotal ( $\mathrm{L} \mathrm{d})^{-1}$ (Figura 3). Com o aumento da COV, nas fases 1; 2 e 3, ocorreram produções volumétricas de $\mathrm{CH}_{4}$ crescentes, como usualmente é observado. SANTANA \& OLIVEIRA (2005), operando reatores UASB em dois estágios, no tratamento de águas residuárias de suinocultura, obtiveram produções volumétricas de metano no $\mathrm{R} 1$ de 0,$594 ; 0,742 ; 0,899$ e $1,130 \mathrm{~m}^{3} \mathrm{CH}_{4}\left(\mathrm{~m}^{3}\right.$ reator $\mathrm{d})^{-1}$ com COV de 3; 5; 7 e $14 \mathrm{~g}$ DQO total $(\mathrm{L} \mathrm{d})^{-1}$. A redução da produção volumétrica de metano com a maior COV ocorreu em virtude da menor proporção de $\mathrm{DQO}_{\text {diss. }}$ em relação a DQO $_{\text {total }}$ do afluente, na fase 2 (Tabela 2), o que também foi citado por OLIVEIRA \& FORESTI (2004). 


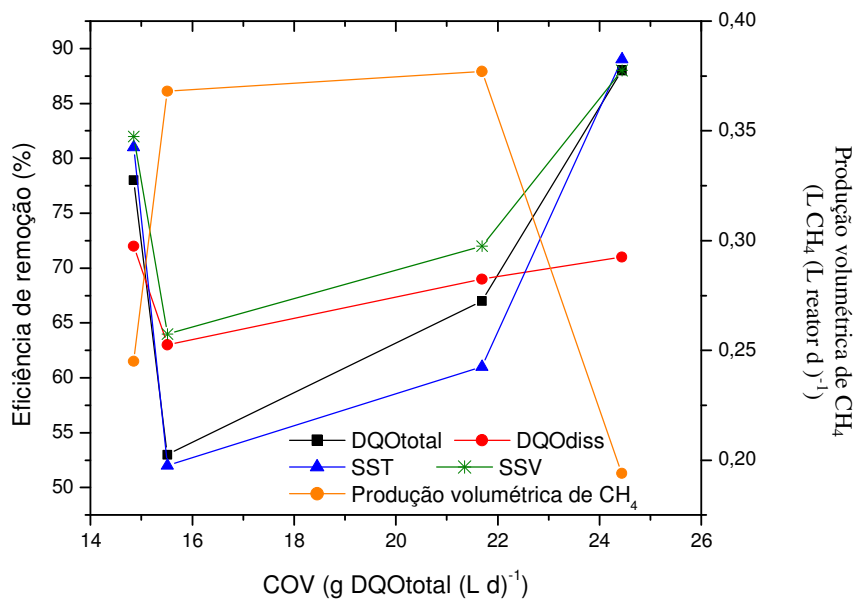

FIGURA 3. Eficiências médias de remoção de $\mathrm{DQO}_{\text {total }}$, $\mathrm{DQO}_{\text {diss }}$, SST, SSV e produção volumétrica de metano no sistema de tratamento anaeróbio em dois estágios com os reatores UASB $(\mathrm{R} 1+\mathrm{R} 2)$, em função das COV aplicadas no R1. Average values of the removal efficiencies of total and dissolved chemical oxygen demands (totalCOD and dissCOD), total and volatile suspended solids (TSS and VSS) during the operation of UASB reactors in series $(\mathrm{R} 1+\mathrm{R} 2)$ in phases $1,2,3$ and 4.

Para o sistema de tratamento combinado anaeróbio e aeróbio $(\mathrm{R} 1+\mathrm{R} 2+\mathrm{RBS})$, foram obtidos valores médios de eficiência de remoção de $\mathrm{DQO}_{\text {total }}$ de 93 a 97 \% (Figura 4). Valores superiores aos encontrados por DENG et al. (2008), os quais avaliaram reator UASB seguido de RBS no tratamento de águas residuárias de suinocultura com DQO de $6.561 \mathrm{mg} \mathrm{L}^{-1}$, com a aplicação de COV de 1,5 a 4,0 $\mathrm{g} \mathrm{DBO}_{5}\left(\mathrm{~L} \mathrm{~d}^{-1}\right)$ no reator UASB, e obtiveram eficiências médias de remoção de DQO $_{\text {total }}$ de 87 a 94\% no sistema combinado anaeróbio e aeróbio, operado com TDH de 6,3 d e temperatura de 20 a $25^{\circ} \mathrm{C}$.

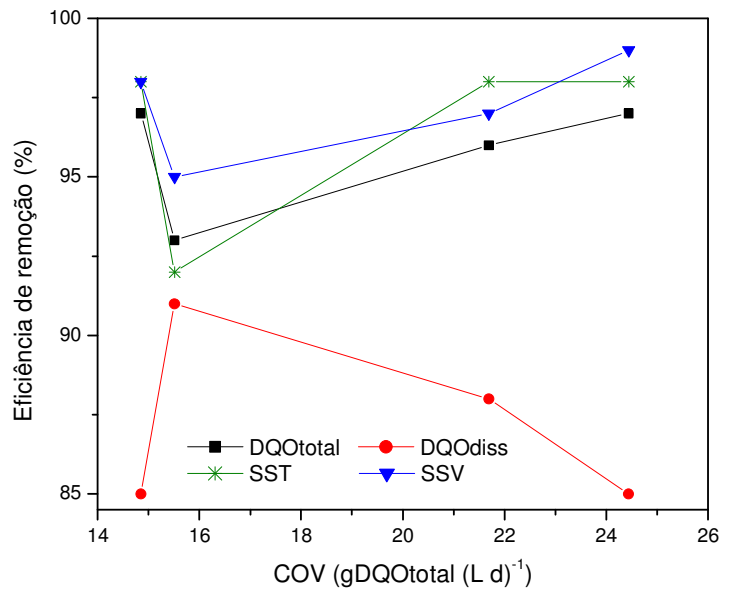

FIGURA 4. Eficiências médias de remoção de DQO $_{\text {total, }}$ DQO ${ }_{\text {diss }}$, SST e SSV para sistema de tratamento anaeróbio em dois estágios com os reatores UASB (R1+R2) e o pós-tratamento (R1+R2+RBS) em função das COV aplicadas no R1. Average values of the removal efficiencies of total and dissolved chemical oxygen demands (totalCOD and dissCOD), total and volatile suspended solids (TSS and VSS) during the operation of UASB reactors in series $(\mathrm{R} 1+\mathrm{R} 2)$ followed by sequential batch reactor (SBR) in phases $1,2,3$ and 4 . 
Isto possibilitou obter, neste trabalho, maiores eficiências no sistema de tratamento $\mathrm{R} 1+\mathrm{R} 2+\mathrm{RBS}$, mesmo com águas residuárias muito mais concentradas, COV superiores e TDH menores (de 2,0 a 4,0 d). Foi a inclusão do reator UASB do segundo estágio (R2) que diminuiu a $\mathrm{DQO}_{\text {total }}$ do afluente do RBS, e da etapa inicial anaeróbia do ciclo do RBS, quando ocorreu o consumo de matéria orgânica pelas bactérias para a desnitrificação.

Os valores médios das concentrações de SST e SSV do afluente foram de 8.270; 16.425; 5.978 e $4.427 \mathrm{mg} \mathrm{L}^{-1}$ e de $6.697 ; 12.282 ; 3.357$ e $2.702 \mathrm{mg} \mathrm{L}^{-1}$, nas fases $1 ; 2 ; 3 \mathrm{e} \mathrm{4}$, respectivamente, indicando a predominância de sólidos suspensos orgânicos (de 56 a $80 \%$ dos SST) nas águas residuárias de suinocultura. Os valores médios de SST e SSV no efluente do R1 diminuíram para $2.482 ; 3.335 ; 1.627$ e $1.778 \mathrm{mg} \mathrm{L}^{-1}$, e para $2.093 ; 2.811 ; 1.019$ e $1.205 \mathrm{mg} \mathrm{L}^{-1}$, nas fases $1 ; 2 ; 3$ e 4 , respectivamente (Tabela 2 ).

As eficiências médias de remoção de SST e SSV no sistema R1+R2 foram de 81 e $52 \%$ e de 82 e $54 \%$ nas fases 1 e 4, com a aplicação de COV similares de 14,8 e 15,5 de DQO $_{\text {total }}(\mathrm{L} \mathrm{d})^{-1}$ e TDH decrescentes de 28 e $14 \mathrm{~h}$, respectivamente. Isto evidencia o efeito acentuado da diminuição do TDH na remoção dos sólidos suspensos do afluente nos reatores anaeróbios. No R2, ocorreram menores eficiências de remoção de SST e SSV, comparado ao R1; entretanto, houve contribuição para a manutenção da estabilidade e das altas eficiências de remoção para o conjunto de reatores anaeróbios (R1+R2), evidenciando a vantagem de aplicar o processo anaeróbio em dois estágios.

No sistema de tratamento combinado anaeróbio e aeróbio (R1+R2+RBS), foram observadas altas eficiências de remoção de SST e SSV, de 98; 98; 98 e 92\% e de 98; 99; 97 e 95\% nas fases 1; 2; 3 e 4, respectivamente. Ficou evidente a estabilidade na redução de concentrações de SST e SSV no efluente durante todo o período de operação dos reatores (Figura 4), mesmo com variações acentuadas no TDH e nos sólidos suspensos do afluente. ZHANG et al. (2006) utilizaram águas residuárias de suinocultura com SST de 1,86 $\mathrm{g} \mathrm{L}^{-1}$ em RBS com ciclo de $8 \mathrm{~h}$ (dividido em etapas anaeróbias, anóxicas/aeróbias e de sedimentação), com TDH de 3,3 d, e obtiveram eficiências de remoção de SST e SSV similares ou menores do que as observadas neste estudo, de 90\% e 93\%, respectivamente. Assim, mesmo com águas residuárias de suinocultura com concentrações de SST maiores e com TDH similares e menores (3,2 e 2,0 d nas fases 3 e 4, respectivamente), as remoções foram próximas ou superiores e confirmam que, com a utilização dos reatores UASB em dois estágios, pode ser possível obter vantagens como diminuir a potência de aeração, requerida na fase aeróbia, diminuir a produção de lodo biológico e o custo de implantação e operação.

Os valores médios do $\mathrm{pH}$ no afluente variaram de 5,7 a 6,0 durante as fases de operação (Tabela 3). Nos efluentes do R1 e R2, os valores de $\mathrm{pH}$ aumentaram para 6,8 a 7,4 e para 7,0 a 7,3, respectivamente, nas fases 1 a 4 (Tabela 3). Segundo CHERNICHARO (2007), a faixa ótima de pH para o desenvolvimento das arqueias metanogênicas é de 6,6 a 7,4, o que ocorreu no R1 e R2, nos quais houve produção de biogás com altas concentrações de metano.

No RBS, o pH do efluente variou de 7,0 a 7,4 nas fases 1 a 4 . O controle do pH no RBS ocorreu através do balanço da alcalinidade, a qual foi consumida durante a nitrificação, na etapa aeróbia e parcialmente recuperada durante a desnitrificação, na etapa anóxica/anaeróbia. No processo de remoção de nitrogênio, é interessante que se mantenha o $\mathrm{pH}$ acima de 6,5; pois é a faixa na qual as bactérias nitrificantes são mais eficientes (METCALF \& EDDY, 2003).

Os valores médios da alcalinidade total (AT) no afluente foram de $1.081 ; 9.37 ; 1.081 ; 665 \mathrm{e}$ $634 \mathrm{mg} \mathrm{L}^{-1}$ durante as fases 1; 2; 3 e 4, respectivamente (Tabela 3). Nos efluentes do R1 e R2, os valores de AT foram maiores, em virtude do aumento da alcalinidade parcial (AP), proporcionando capacidade tampão aos reatores. A alcalinidade intermediária (AI) foi reduzida pelo consumo dos ácidos graxos de cadeia curta pela microbiota dos reatores anaeróbios. No RBS, ocorreu consumo médio de AT de 966; 742; 654 e $738 \mathrm{mg} \mathrm{L}^{-1}$, nas fases 1;2; 3 e 4, respectivamente. O decréscimo significativo dos valores da alcalinidade no RBS ocorreu em virtude da nitrificação. 
TABELA 3. Valores médios e coeficientes de variação (C.V.) da alcalinidade total (AT), alcalinidade parcial (AP) e alcalinidade intermediária (AI), em $\mathrm{mg} \mathrm{CaCO}_{3} \mathrm{~L}^{-1}$, obtidos durante a operação do sistema de tratamento com reatores UASB, em dois estágios (R1 e R2), seguidos de reator operado em batelada sequencial (RBS), nas fases $1 ; 2 ; 3$ e 4. Average values and variation coefficients (c.v.) of the total alkalinity (TA), partial alkalinity (PA), intermediary alkalinity in the influent and effluents during the operation of UASB reactors in series $(\mathrm{R} 1+\mathrm{R} 2)$ followed by sequential batch reactor (SBR) in phases 1, 2, 3 and 4 .

\begin{tabular}{|c|c|c|c|c|c|c|c|c|c|}
\hline \multirow{2}{*}{\multicolumn{2}{|c|}{ Parâmetros }} & \multicolumn{2}{|c|}{ Fase 1} & \multicolumn{2}{|c|}{ Fase 2} & \multicolumn{2}{|c|}{ Fase 3} & \multicolumn{2}{|c|}{ Fase 4} \\
\hline & & Média & C.V. & Média & C.V. & Média & C.V. & Média & C.V. \\
\hline \multirow{4}{*}{ AT } & Afluente & 1.081 & 49 & 937 & 54 & 665 & 24 & 634 & 24 \\
\hline & $\mathrm{R} 1$ & 1.262 & 46 & 1.104 & 34 & 916 & 14 & 914 & 17 \\
\hline & $\mathrm{R} 2$ & 1.313 & 37 & 1.075 & 23 & 934 & 14 & 950 & 20 \\
\hline & RBS & 347 & 95 & 333 & 92 & 280 & 58 & 212 & 58 \\
\hline \multirow{4}{*}{ AP } & Afluente & 167 & 110 & 68 & 168 & 117 & 83 & 110 & 61 \\
\hline & R1 & 851 & 56 & 590 & 27 & 605 & 20 & 517 & 28 \\
\hline & R2 & 960 & 47 & 610 & 27 & 660 & 33 & 613 & 35 \\
\hline & RBS & 283 & 131 & 241 & 96 & 216 & 54 & 154 & 57 \\
\hline \multirow{4}{*}{ AI } & Afluente & 914 & 44 & 869 & 56 & 547 & 23 & 524 & 24 \\
\hline & R1 & 410 & 46 & 514 & 66 & 311 & 32 & 398 & 33 \\
\hline & $\mathrm{R} 2$ & 353 & 41 & 465 & 51 & 274 & 20 & 337 & 32 \\
\hline & RBS & 64 & 82 & 92 & 91 & 64 & 96 & 59 & 73 \\
\hline
\end{tabular}

As concentrações médias de NTK no afluente do R1 foram de 906, 1.102, 560 e $487 \mathrm{mg} \mathrm{L}^{-1}$ nas fases 1;2; 3 e 4, respectivamente, e em média 70 a $80 \%$ estava na forma orgânica (N-org.) e 20 a $30 \%$ na forma amoniacal $(\mathrm{N}$-am.) (Tabela 4). Após o tratamento anaeróbio, nos reatores UASB em dois estágios, a fração de NTK na forma amoniacal representou 48 a $66 \%$, com valores médios de 202 a $320 \mathrm{mg} \mathrm{L}^{-1}$ no efluente do R2, confirmando a alta taxa de amonificação do N-org.

No efluente do R2, os valores médios da concentração de NTK diminuíram para 505; 384, 448 e $396 \mathrm{mg} \mathrm{L}^{-1}$, nas fases 1; 2; 3 e 4, respectivamente, resultando em remoções de 21 a $63 \%$, nas fases 1 a 4 no R1+R2 (Tabela 4 e Figura 5). Nas fases 3 e 4, houve decréscimo na eficiência de remoção de NTK para $21 \%$ no R1 + R2, em decorrência do aumento da concentração de SST para 1.844 e $2.036 \mathrm{mg} \mathrm{L}^{-1}$ (Tabela 3), respectivamente, no efluente do R2, devido ao arraste de lodo em consequência da diminuição do TDH de 11 h para 6 h no R2.

Os maiores valores médios das eficiências de remoção de NTK, de 47 e 63\%, e de N-org., de 70 e $84 \%$, ocorreram nas fases 1 e 2 (Figura 5) com TDH de 39 h no R1+R2. RAMIRES (2005) obteve eficiências de remoção similares de NTK e N-org., de 46 a 58\% e de 82 a 93\%, respectivamente, aplicando TDH de $43 \mathrm{~h} 30$ em reatores UASB em dois estágios, tratando águas residuárias de suinocultura, com concentrações médias de NTK de 478 a $1.588 \mathrm{mg} \mathrm{L}^{-1}$. Com a diminuição do TDH, houve queda nas remoções de NTK e N-org., indicando que mecanismos de sedimentação e interceptação na manta de lodo estão associados à redução da concentração de Norg. no efluente dos reatores anaeróbios (R1 e R2). OLIVEIRA (1997) e DENG et al. (2008) também atribuíram parte da remoção de NTK à formação de estrovita $\left(\mathrm{MgNH}_{4} \mathrm{PO}_{4} \cdot 6 \mathrm{H}_{2} \mathrm{O}\right)$ a partir de $\mathrm{N}$-am., fosfato e magnésio.

Para o RBS alimentado com concentrações de NTK de 505 e $384 \mathrm{mg} \mathrm{L}^{-1}$ nas fases 1 e 2, foram observados valores médios no efluente de 88 e $96 \mathrm{mg} \mathrm{L}^{-1}$ (Tabela 4), resultando em eficiências médias de remoção de 83 e $69 \%$, respectivamente. Nas fases 3 e 4, nas quais o RBS foi operado com ciclos de $24 \mathrm{~h}$ e $12 \mathrm{~h}$, e COV de 1,7 e 4,5 g DQO total $(\mathrm{L} \mathrm{d})^{-1}$, as eficiências de remoção de NTK foram de 72 e $74 \%$, respectivamente. Para o N-org. observaram-se menores valores de remoção, de 53 e 56\%, nas fases 3 e 4, respectivamente (Figura 5). 
TABELA 4. Valores médios e coeficientes de variação (C.V.), das concentrações de nitrogênio total Kjeldahl (NTK), nitrogênio amoniacal $\left(\mathrm{N}-\mathrm{NH}_{3}\right)$, nitrogênio orgânico (N-org.), nitrogênio total (NT), nitrito $\left(\mathrm{N}-\mathrm{NO}_{2}{ }^{-}\right)$, nitrato $\left(\mathrm{N}-\mathrm{NO}_{3}{ }^{-}\right)$, oxigênio dissolvido (OD) e vazão de ar $\left(\mathrm{Q}_{\mathrm{ar}}\right)$, no afluente e efluentes, obtidos durante a operação do sistema de tratamento com reatores UASB em dois estágios (R1 e R2), seguidos do reator operado em batelada sequencial (RBS) aeróbio, nas fases 1;2; 3 e 4. Average values and variation coefficients (c.v.) of total Kjeldahl nitrogen (TKN), ammoniacal nitrogen (am. $\mathrm{N}$ ), organic nitrogen (org. $\mathrm{N}$ ); total nitrogen $(\mathrm{TN})$, nitrite $\left(\mathrm{N}_{-} \mathrm{NO}_{2}{ }^{-}\right.$), nitrate $\left(\mathrm{N}-\mathrm{NO}_{3}{ }^{-}\right)$, dissolved oxygen (DO) and air flux (air Q) in the influent and effluents, during the operation of UASB reactors in series (R1 and R2) followed by sequential batch reactor (SBR) in phases $1,2,3$ and 4 .

\begin{tabular}{|c|c|c|c|c|c|c|c|c|c|}
\hline \multirow{2}{*}{\multicolumn{2}{|c|}{ Parâmetros }} & \multicolumn{2}{|c|}{ Fase 1} & \multicolumn{2}{|c|}{ Fase 2} & \multicolumn{2}{|c|}{ Fase 3} & \multicolumn{2}{|c|}{ Fase 4} \\
\hline & & Média & C.V. & Média & C.V. & Média & C.V. & Média & C.V \\
\hline \multirow{4}{*}{ NTK $\left(\mathrm{mg} \mathrm{L}^{-1}\right)$} & Afluente & 906 & 39 & 1.102 & 41 & 560 & 24 & 487 & 18 \\
\hline & R1 & 504 & 25 & 440 & 45 & 335 & 38 & 347 & 54 \\
\hline & $\mathrm{R} 2$ & 505 & 42 & 384 & 38 & 448 & 48 & 396 & 38 \\
\hline & RBS & 88 & 126 & 96 & 75 & 115 & 98 & 110 & 71 \\
\hline \multirow{4}{*}{$\mathrm{N}$-am. $\left(\mathrm{mg} \mathrm{L}^{-1}\right)$} & Afluente & 270 & 40 & 214 & 32 & 153 & 22 & 157 & 24 \\
\hline & $\mathrm{R} 1$ & 299 & 44 & 255 & 31 & 204 & 21 & 204 & 18 \\
\hline & R2 & 320 & 37 & 256 & 32 & 202 & 18 & 208 & 20 \\
\hline & RBS & 28 & 87 & 27 & 49 & 8 & 88 & 11 & 155 \\
\hline \multirow{4}{*}{ N-org. $\left(\mathrm{mg} \mathrm{L}^{-1}\right)$} & Afluente & 636 & 53 & 888 & 47 & 408 & 35 & 330 & 30 \\
\hline & $\mathrm{R} 1$ & 218 & 40 & 185 & 82 & 131 & 47 & 142 & 49 \\
\hline & R2 & 185 & 110 & 140 & 90 & 245 & 63 & 188 & 79 \\
\hline & RBS & 60 & 60 & 69 & 147 & 106 & 34 & 99 & 27 \\
\hline \multirow{2}{*}{$\mathrm{NT}\left(\mathrm{mg} \mathrm{L}^{-1}\right)$} & R2 & 505 & 42 & 384 & 38 & 448 & 48 & 396 & 38 \\
\hline & RBS & 143 & 60 & 129 & 62 & 145 & 23 & 148 & 39 \\
\hline $\mathrm{N}-\mathrm{NO}_{2}{ }^{-}\left(\mathrm{mg} \mathrm{L}^{-1}\right)$ & \multirow{4}{*}{ RBS } & 12 & 130 & 6 & 127 & 5 & 112 & 7 & 74 \\
\hline $\mathrm{N}^{-\mathrm{NO}_{3}}{ }^{-}\left(\mathrm{mg} \mathrm{L}^{-1}\right)$ & & 45 & 20 & 42 & 33 & 26 & 76 & 39 & 38 \\
\hline $\mathrm{OD}\left(\mathrm{mg} \mathrm{L}^{-1}\right)$ & & 3 & 56 & 3 & 98 & 2 & 42 & 2 & 70 \\
\hline $\mathrm{Q}_{\mathrm{ar}}\left(\mathrm{m}^{3} \mathrm{~h}^{-1}\right)$ & & 2 & 57 & 2 & 35 & 1,6 & 37 & 2 & 38 \\
\hline
\end{tabular}

Com base nesses resultados, pode-se inferir que houve alta atividade nitrificante durante as fases de operação do RBS, confirmada pela redução acentuada nas concentrações de N-am., com remoções médias de 89 a 96\% (Tabela 4 e Figura 6). Nas fases 3 e 4, as concentrações médias de $\mathrm{N}$-am. no efluente do RBS foram de 8 e $11 \mathrm{mg} \mathrm{L}^{-1}$, respectivamente, atendendo ao padrão de lançamento de efluentes de $20 \mathrm{mg} \mathrm{L}^{-1}$ de N-am., estabelecido na Resolução 357 do Conselho Nacional de Meio Ambiente (CONAMA) (BRASIL, 2005).

PEREIRA-RAMIREZ et al. (2003) avaliaram um sistema de lodos ativados com TDH de $4 \mathrm{~d}$, para tratar águas residuárias de suinocultura, provenientes de sistema composto por reator UASB e filtro anaeróbio instalados em série, com valores médios de $\mathrm{DQO}_{\text {total }}$ de $854 \mathrm{mg} \mathrm{L}^{-1}$, de NTK de $402 \mathrm{mg} \mathrm{L}^{-1}$, de $\mathrm{N}$-am. de $398 \mathrm{mg} \mathrm{L}^{-1}$ e de alcalinidade total de $3.812 \mathrm{mg} \mathrm{CaCO}_{3} \mathrm{~L}^{-1}$. Obtiveram eficiências de remoção de NTK e N-am. acima de $96 \%$. Para a remoção de $\mathrm{N}$-am., foi possível obter valores similares (de 89 a 96\%) nas fases 1; 2 e 3, mesmo com TDH menor no RBS (de 2,3 d) e com aeração intermitente.

Considerando o sistema de tratamento combinado (R1+R2+RBS), os valores médios de eficiência de remoção para NTK, N-org. e N-am. variaram de 86 a 95\% nas fases 1 e 2, e de $71 \%$ a 95\% nas fases 3 e 4 (Figuras 5 e 6). DENG et al. (2008), para aumentar a remoção de $\mathrm{N}$-am. de $72 \%$, para $92 \%$ e $99 \%$ no sistema de tratamento com reator UASB, com TDH de 3,0 d, seguido de RBS, com TDH de 3,3 d e ciclo de $8 \mathrm{~h}$ (4 h de aeração), adicionaram alcalinizante $\left(1 \mathrm{~g} \mathrm{~L}^{-1} \mathrm{de}\right.$ carbonato de sódio) ou água residuária de suinocultura bruta (33\% em volume) ao efluente anaeróbio que alimentava o RBS. Com a utilização dos reatores UASB em dois estágios, não foi 
necessário qualquer incremento no efluente anaeróbio para alcançar remoções similares, mesmo utilizando águas residuárias de suinocultura mais concentradas.

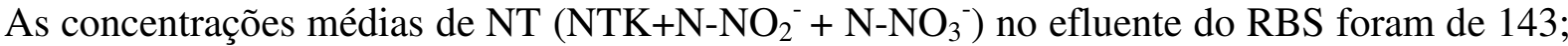
129; 145 e $148 \mathrm{mg} \mathrm{L}^{-1}$ nas fases $1 ; 2 ; 3$ e 4, respectivamente, valores estes menores que os do afluente (efluente do R2), de 505; 384; 448 e $393 \mathrm{mg} \mathrm{L}^{-1}$ (Tabela 4), em consequência das eficiências médias de remoção de NT no RBS, de 68; 64; 65 e 58\%, com COV de 1,6;1,4; 1,7 e 4,5 $\mathrm{g} \mathrm{DQO}_{\text {total }}(\mathrm{L} \mathrm{d})^{-1}$, respectivamente, nas fases $1 ; 2 ; 3$ e 4 . O aumento da COV no RBS, na fase 4, não provocou diminuição acentuada na remoção de NT. Ocorreu redução acentuada da concentração de $\mathrm{N}$-am. no efluente do RBS, proporcionalmente ao acúmulo reduzido de N-nítrico $\left(\mathrm{N}-\mathrm{NO}_{2}{ }^{-}+\mathrm{N}^{-\mathrm{NO}_{3}}{ }^{-}\right)$, indicando que ocorreu, além da imobilização no lodo e da nitrificação, a desnitrificação.

A quantidade de alcalinidade requerida para a nitrificação depende da concentração inicial e da quantidade de $\mathrm{N}$-am. a ser oxidada. A alcalinidade requerida, descontando-se a parte do Namoniacal convertido em nitrogênio celular, é de $7,07 \mathrm{~g} \mathrm{CaCO}_{3}$ por $\mathrm{g}$ de $\mathrm{N}$-am. convertido a nitrato (METCALF \& EDDY, 2003). Dessa forma, as quantidades de alcalinidade requeridas para a nitrificação do NTK removido no RBS foram de 2.948; 2.036, 2.354 e $2.022 \mathrm{mg} \mathrm{CaCO}_{3}$ nas fases 1; 2; 3 e 4, respectivamente, valores superiores aos da alcalinidade no efluente do R2 (Tabela 3).

A concentração de nitrito diminuiu da fase 1 para a fase 2 , de 12 para $6 \mathrm{mg} \mathrm{L}^{-1}$, respectivamente, e depois nas fases 3 e 4 permaneceu com valores médios menores, de 5 e $7 \mathrm{mg} \mathrm{L}^{-1}$, respectivamente, evidenciando que, a partir da fase 2 , ocorreram condições mais favoráveis para a nitratação. Para os teores de nitrato, os valores médios foram de 45; 42; 26 e $39 \mathrm{mg} \mathrm{L}^{-1}$ nas fases 1 ; 2; 3 e 4, respectivamente. Os valores médios de nitrito, nas quatro fases de operação, menores que os valores médios de nitrato, indicam que houve condições ambientais para que a maior parte do $\mathrm{N}$-am. fosse oxidada até nitrato, mesmo com limitação da alcalinidade

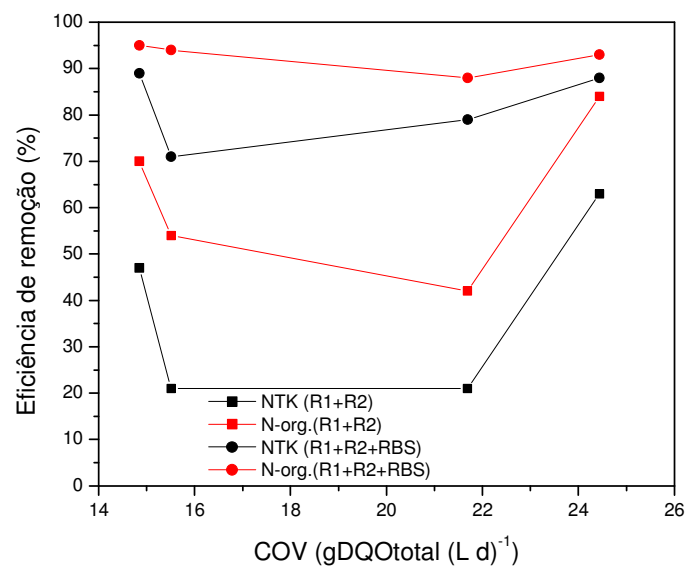

FIGURA 5. Eficiências médias de remoção de NTK e N-org. para sistema de tratamento anaeróbio em dois estágios com os reatores UASB $(\mathrm{R} 1+\mathrm{R} 2)$ e o pós-tratamento (R1+R2+RBS) em função das COV aplicadas no R1. Average values of the removal efficiencies of total Kjedahl nitrogen (TKN) and organic nitrogen (org-N) during the operation of UASB reactors in series $(\mathrm{R} 1+\mathrm{R} 2)$ followed by sequential batch reactor $(\mathrm{SBR})$ in phases $1,2,3$ and 4 .

De acordo com WU et al. (2007), as concentrações de N-am. e a temperatura afetam o acúmulo de nitrito no sistema. A amônia livre limita o processo de nitrificação em virtude da alcalinidade. Na fase 1, ocorreram as maiores concentrações médias de $\mathrm{N}$-am. no afluente do RBS (Tabela 4), as menores temperaturas médias do ar (Tabela 2) e, consequentemente, as concentrações mais elevadas de N-nítrico no efluente do RBS. 
As concentrações médias de oxigênio dissolvido no RBS variaram de 2 a $3 \mathrm{mg} \mathrm{L}^{-1}$ na etapa aeróbia, durante as quatro fases de operação (Tabela 4). A concentração mínima de oxigênio no interior do líquido, para manter um ambiente aeróbio para os microrganismos, depende de vários fatores: tamanho do floco, intensidade de agitação, temperatura e, principalmente, da taxa de consumo de oxigênio (VAN HAANDEL \& MARAIS, 1999). Os autores citaram que a concentração mínima de OD para que ocorra a nitrificação é de $2 \mathrm{mg} \mathrm{L}^{-1}$, o que foi atendido. Para tanto, a vazão média de ar na etapa aeróbia foi de 1,6 a $2,0 \mathrm{~m}^{3} \mathrm{~h}^{-1}$, ou seja; 7,6 a $9,5 \mathrm{~m}^{3}$ $\left(\mathrm{m}^{3} \text { reator } \mathrm{h}\right)^{-1}$.

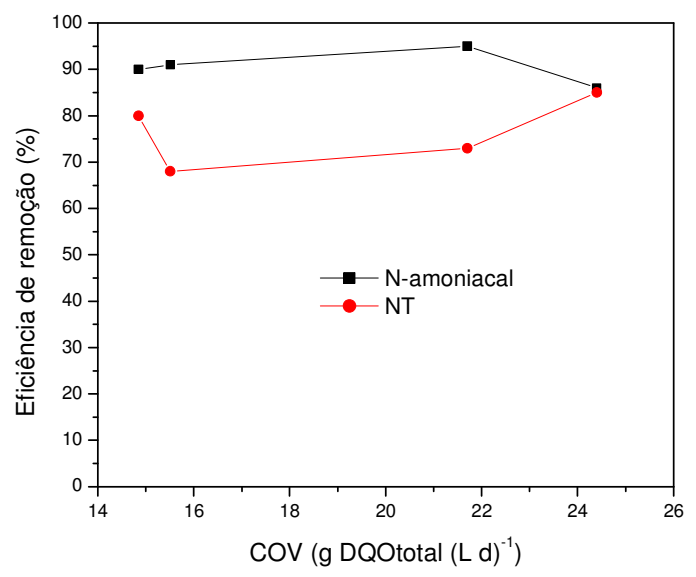

FIGURA 6. Eficiências médias de remoção de N-am. e NT no sistema de tratamento anaeróbio e pós-tratamento (R1+R2+RBS) em função das COV aplicadas no R1. Average values of the removal efficiencies of ammoniacal nitrogen (am.-N) and total nitrogen (TN) during the operation of UASB reactors in series $(\mathrm{R} 1+\mathrm{R} 2)$ followed by sequential batch reactor (SBR) in phases $1,2,3$ and 4.

Os valores médios da concentração de fósforo total (P-total) no afluente do sistema de tratamento anaeróbio diminuíram de 400 e $756 \mathrm{mg} \mathrm{L}^{-1}$, nas fases 1 e 2 , para 266 e $254 \mathrm{mg} \mathrm{L}^{-1}$, nas fases 3 e 4, respectivamente (Tabela 5), em virtude das variações nas concentrações de SST das águas residuárias de suinocultura. Nas fases 1 a 4, os valores médios da concentração de P-total no efluente diminuíram em virtude de remoções no R1, de 49 a 59\%, respectivamente. OLIVEIRA (1997) e DENG et al. (2008) atribuíram a remoção de P à sedimentação de sólidos e precipitação com alumínio, cálcio, ferro ou magnésio, e também em virtude da formação de fosfina em condições anaeróbias. No R2, em decorrência dos baixos TDH (11 e 6 h), ocorreu arraste de lodo e, consequentemente, houve acréscimo na concentração de P-total no efluente, exceto na fase 2.

Para o conjunto de reatores (R1+R2), as eficiências de remoção de P-total foram de 47; 57; 29 e $28 \%$, nas fases $1 ; 2 ; 3$ e 4, respectivamente. Houve influência das maiores concentrações de Ptotal no afluente e do maior TDH no R2, nas fases 1 e 2 , no aumento da eficiência de remoção. RAMIRES (2005) obteve maiores remoções de P-total (de 70 a 75\%), em reatores UASB, em dois estágios, com TDH de $43 \mathrm{~h} 30$ e concentrações de P-total no afluente de 162 a $337 \mathrm{mg} \mathrm{L}^{-1}$, indicando que a retenção e/ou precipitação de P-total na manta de lodo é intensificada com maiores tempos de contato.

No RBS, as eficiências de remoção do P-total foram de 43; 65; 66 e 58\% nas fases $1 ; 2 ; 3$ e 4, respectivamente. PEREIRA-RAMIREZ et al. (2003), no reator biológico com aeração contínua, com TDH de $4 \mathrm{~d}$, alimentado com águas residuárias de suinocultura provenientes de sistema composto por reator UASB e filtro anaeróbio instalados em série, com concentração média de $67 \mathrm{mg} \mathrm{L}^{-1}$, obtiveram somente $26 \%$ de remoção de P-total. Dessa forma, com o RBS, da maneira como foi operado, foi possível obter maiores remoções de P-total, com menor gasto de energia, considerando-se que a aeração no RBS foi intermitente. 
TABELA 5. Valores médios e coeficientes de variação (C.V.) das concentrações de fósforo total (Ptotal) no afluente e nos efluentes, e das eficiências de remoção de P-total, obtidos durante a operação do sistema de tratamento com reatores UASB, em dois estágios (R1 e R2), seguidos do reator em batelada sequencial (RBS), nas fases $1 ; 2 ; 3$ e 4. Average values and variation coefficients (c.v.) of the total phosphorus in the influent and effluents, during the operation of UASB reactors in series (R1 and R2) followed by an aerobic sequential batch reactor (SBR) in phases 1, 2, 3 and 4.

\begin{tabular}{|c|c|c|c|c|c|c|c|c|c|}
\hline \multirow{3}{*}{ Fases } & \multicolumn{4}{|c|}{$\mathrm{P}-$ total $\left(\mathrm{mg} \mathrm{L}^{-1}\right)$} & \multirow{2}{*}{\multicolumn{5}{|c|}{ Eficiência de Remoção (\%) }} \\
\hline & \multirow{2}{*}{ Afluente } & \multicolumn{3}{|c|}{ Efluente } & & & & & \\
\hline & & $\mathrm{R} 1$ & $\mathrm{R} 2$ & RBS & $\mathrm{R} 1$ & $\mathrm{R} 2$ & $\mathrm{R} 1+\mathrm{R} 2$ & RBS & Sistema* \\
\hline 1 & 400 & 220 & 240 & 122 & 49 & - & 47 & 43 & 57 \\
\hline 2 & 756 & 462 & 457 & 160 & 52 & - & 57 & 66 & 58 \\
\hline 3 & 266 & 103 & 181 & 78 & 59 & - & 29 & 66 & 74 \\
\hline 4 & 254 & 120 & 209 & 85 & 53 & - & 28 & 58 & 64 \\
\hline \multirow{4}{*}{$\begin{array}{c}\text { C.V. } \\
(\%)\end{array}$} & 40 & 42 & 31 & 30 & 33 & - & 34 & 42 & 19 \\
\hline & 53 & 74 & 66 & 42 & 39 & - & 44 & 26 & 23 \\
\hline & 25 & 18 & 14 & 95 & 19 & - & 59 & 33 & 24 \\
\hline & 38 & 46 & 34 & 57 & 28 & - & 120 & 45 & 36 \\
\hline
\end{tabular}

* sistema de tratamento combinado (R1+R2+RBS)

No sistema de tratamento combinado $(\mathrm{R} 1+\mathrm{R} 2+\mathrm{RBS})$, foram observadas eficiências médias de remoção de P-total de 57; 58; 74 e 64 nas fases 1; 2; 3 e 4, respectivamente. DENG et al. (2008) obtiveram remoções de P-total similares, de 49 a $71 \%$, no sistema de tratamento com reator UASB e RBS, com TDH maior, de 6,3 d, e com concentrações menores, de $125 \mathrm{mg} \mathrm{L}^{-1}$ de P-total no afluente. Já ZHANG et al. (2006), com o RBS com TDH de 3,3 d e 91,8 $\mathrm{mg} \mathrm{L}^{-1}$ de P-total no afluente, alcançaram remoções de $98 \%$, em virtude de utilizarem o ciclo de $8 \mathrm{~h}$ divido em várias etapas $(1 \mathrm{~h}$ e $15 \mathrm{~min}$ anaeróbia, $2 \mathrm{~h}$ e $45 \mathrm{~min}$ anóxica/aeróbia, $1 \mathrm{~h}$ e $30 \mathrm{~min}$ anaeróbia, $2 \mathrm{~h}$ anóxica/aeróbia e 30 min de sedimentação), o que melhorou acentuadamente a remoção de P-total.

Neste estudo, foram observados valores médios de eficiências de remoção de DQO, SST, NTK, N-am., NT e P-total, principalmente, similares ou superiores aos resultados obtidos por PEREIRA-RAMIREZ et al. (2003), ZHANG et al. (2006) e DENG et al. (2008), mesmo tratando águas residuárias de suinocultura com DQO e SST mais elevadas, e com maiores COV e menores TDH aplicados nos reatores. Quando os resultados foram inferiores, pôde ser atribuído aos altos valores das COV e baixos TDH aplicados nos reatores UASB, à menor aeração no RBS e ao uso de ciclos mais longos, com 24 e 12 h, e somente com uma etapa anaeróbia e uma de aeração.

Os valores médios dos números de coliformes termotolerantes no afluente foram de 4,3x $10^{8}$; $1,5 \times 10^{7} ; 4,6 \times 10^{7}$ e 4,3x $10^{8} \mathrm{NMP} / 100 \mathrm{~mL}$ nas fases $1 ; 2 ; 3$ e 4 , respectivamente. Nos efluentes do $\mathrm{R} 1$, os coliformes termotolerantes diminuíram para 4,3x $10^{7} ; 4,3 \times 10^{6} ; 4,6 \times 10^{6}$ e 4,6x $10^{6} \mathrm{NMP} / 100 \mathrm{~mL}$, nas fases $1 ; 2 ; 3$ e 4, respectivamente. No efluente do R2, mantiveram-se ou aumentaram para $4,3 \times 10^{7} ; 4,3 \times 10^{6} ; 2,4 \times 10^{6}$ e $4,3 \times 10^{7} \mathrm{NMP} / 100 \mathrm{~mL}$ nas fases $1 ; 2 ; 3$ e 4, respectivamente, em virtude dos menores TDH.

Com o RBS, as eficiências de remoção de coliformes termotolerantes aumentaram para 99,99; 93,80; 99,98 e 99,90\%, atingindo concentrações no efluente final de $2,3 \times 10^{4} ; 9,3 \times 10^{5} ; 9,3 \times 10^{3} \mathrm{e}$ 9,3× $10^{3} \mathrm{NMP} / 100 \mathrm{~mL}$ nas fase $1 ; 2 ; 3 \mathrm{e} \mathrm{4}$, respectivamente. PEREIRA-RAMIREZ et al. (2003) alcançaram concentrações menores no efluente final, de $1,8 \times 10^{3} \mathrm{NMP} / 100 \mathrm{~mL}$, possivelmente em virtude da aeração contínua no sistema de lodos ativados.

\section{CONCLUSÕES}

Com a utilização dos reatores anaeróbios de fluxo ascendente com manta de lodo (UASB), em dois estágios, foi possível obter eficiências de remoção DQO $_{\text {total }}$ e SST acima de $80 \%$, com cargas 
orgânicas volumétricas (COV) altas, de até $24,4 \mathrm{~g} \mathrm{DQO}_{\text {total }}(\mathrm{L} \mathrm{d})^{-1}$, e TDH de 28 h, no R1.

O pós-tratamento do efluente dos reatores UASB em dois estágios, com a utilização do RBS submetido a COV de 1,4 a 4,5 $\mathrm{g} \mathrm{DQO}_{\text {total }}(\mathrm{L} \mathrm{d})^{-1}$, foi eficiente, promovendo melhoria acentuada na qualidade física, química e microbiológica do efluente final, alcançando, com ciclos de $24 \mathrm{~h}$, eficiências médias de remoção acima de $73 \%, 84 \%, 43 \%$ e 69\%, e com ciclo de 12 h, acima de 85;

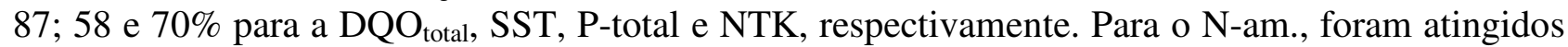
valores abaixo do padrão de lançamento de efluentes estabelecido na legislação federal, como consequência da eficiente nitrificação e desnitrificação que ocorreram no RBS.

O sistema de tratamento combinado anaeróbio e aeróbio, composto pelos reatores UASB em dois estágios seguidos do RBS, mesmo com baixos TDH (39 e $20 \mathrm{~h}$ ), foi muito eficiente na remoção de matéria orgânica (até $97 \%$ para a $\mathrm{DQO}_{\text {total }}$ ), nutrientes (até $89 \%$ para o NTK, 95\% para o N-am. e 74\% para o P-total) e coliformes (até 99,99\%). Dessa forma, pode ser recomendado como alternativa para o tratamento com estabilidade de águas residuárias de suinocultura com grandes variações de carga de sólidos suspensos e com altas concentrações de matéria orgânica, nitrogênio, fósforo e coliformes.

\section{AGRADECIMENTOS}

À FAPESP e à TIGRE S.A., pelo auxílio financeiro.

\section{REFERÊNCIAS}

APHA, AWWA, WPCF. Standard methods for the examination of water and wastewater. $18^{\text {th }}$ ed., Washington, 1998.

BERNET, N.; DELGENES, N.; AKUNNA, J. C.; DELGENES, J. P. Combined anaerobic-aerobic SBR for the treatment of piggery wastewater. Water Research, New York, v.34, n.2, p.611-619, 2000.

BRASIL. Resolução n⿳ำ 357, de 17 de março de 2005. Dispõe sobre a classificação dos corpos de água e diretrizes ambientais para o seu enquadramento, bem como estabelece as condições e padrões de lançamento de efluentes e dá outras providências. Diário Oficial [da] República Federativa do Brasil, Poder legislativo, Brasília-DF, 18 de mar. Seção 1, p.58.

CHERNICHARO, C.A.L. de (Coord.). Pós-tratamento de efluentes de reatores anaeróbios. Belo Horizonte: FINEP, 2001. 544 p.

CHERNICHARO, C.A.L. Post-treatment options for the anaerobic treatment of domestic wastewater. Reviews in Environmental Science and Bio/Technology, v.5, p.73-92, 2006.

CHERNICHARO, C.A.L. de. Reatores anaeróbios: princípios do tratamento biológico de águas residuárias. 2.ed. Belo Horizonte: Departamento de Engenharia Sanitária e Ambiental, Universidade Federal de Minas Gerais, 2007. 379 p.

DENG, L.W.; ZHENG, P.; CHEN, Z.A.; MAHMOOD, Q. Improvement in post-treatment of digested swine wastewater. Bioresource Technology, Barking, v.99, n.8, p.3.136-3.145, 2008.

DUDA, R.M.; OLIVEIRA, R.A. de. Reatores anaeróbios operados em batelada sequencial, seguidos de lagoas de polimento, para o tratamento de águas residuárias de suinocultura. Parte I: produção de metano e remoção de DQO e de sólidos suspensos. Engenharia Agrícola, Jaboticabal, v.29, n.1, p.122-134, 2009.

JENKINS, S.R.; MORGAN, J.M.; SAWYER, C.L. Measuring anaerobic sludge digestion and growth by a simple alkalimetric titration. Journal Water Pollution Control Federal, Alexandria, v.55, n.5, p.448-453, 1983.

MASCARENHAS, L.C.A.; VON SPERLING, M.; CHERNICHARO, A.L. Avaliação do desempenho de lagoas de polimento rasa, em série, para o pós-tratamento de efluentes de reator 
UASB. Engenharia Sanitária e Ambiental, Rio de Janeiro, v.9, n.1, p.45-54, 2004.

METCALF; EDDY. Wastewater engineering: treatment, disposal and reuse. $4^{\text {th }} \mathrm{ed}$. New York: McGraw-Hill, 2003. 1.819 p.

OLIVEIRA, R.A. de. Efeito da concentração de sólidos suspensos do afluente no desempenho e características do lodo de reatores anaeróbios de fluxo ascendente com manta de lodo tratando águas residuárias de suinocultura. São Carlos, 1997. 359 f. Tese. (Doutorado em Hidráulica e Saneamento) - Escola de Engenharia de São Carlos, Universidade de São Paulo, São Carlos, 1997.

OLIVEIRA, R.A. de; FORESTI, E. Balanço de massa de reatores anaeróbios de fluxo ascendente com manta de lodo (UASB) tratando águas residuárias de suinocultura. Revista Brasileira de Engenharia Agrícola, Jaboticabal, v.24, n.3, p.807-820, 2004.

PEREIRA-RAMIREZ, O.; ANTUNES, R.M.; QUADRO, M.S.; KOETZ, P.R. Remoção da DQO e nitrificação em reator biológico aerado no pós-tratamento de águas residuárias de suinocultura. Revista Brasileira Agrociência, Pelotas, v.9, n.3, p.279-286, 2003.

RAMIRES, R.D.A. Produção de metano e remoção de matéria orgânica, nutrientes e microrganismos patogênicos em reatores anaeróbios de fluxo ascendente com manta de lodo (UASB) em dois estágios tratando águas residuárias de suinocultura. 2005. 136 f. Dissertação (Mestrado em Microbiologia Agropecuária) - Faculdade de Ciências Agrárias e Veterinárias, Universidade Estadual Paulista, Jaboticabal, 2005.

SANTANA, A.M. de; OLIVEIRA, R.A. de. Desempenho de reatores anaeróbios de fluxo ascendente com manta de lodo em dois estágios tratando águas residuárias de suinocultura. Engenharia Agrícola, Jaboticabal, v.25, n.3, p.817-830, 2005.

UNIVERSIDADE ESTADUAL PAULISTA. Faculdade de Ciências Agrárias e Veterinárias. Departamento de Ciências Exatas. Estação Agroclimatológica: valores médios do período de 1971 2000. Disponível em <www,fcav.unesp.br/estacao> Acesso em: 10 jun. 2009.

VAN HAANDEL, A.C.; MARAIS, G. O comportamento do sistema de lodo ativado. Campina Grande: Epgraf, 1999. p.472.

ZHANG, Z.; ZHU, J.; KING, J.; LI, W. Two-step fed SBR for treating swine manure. Process Biochemistry, London, v.41, p.892-900, 2006.

WU, C.; CHEN, Z.A.; LIU, X.A.; PENG,Y.B. Nitrification-denitrification via nitrite in SBR using real-time control strategy when treating domestic wastewater. Biochemical Engineering Journal, Beijing, v.7, p.1.010-1.016, 2007. 